\title{
Synechiae of the Oral Cavity with Cleft Palate: A Rare Congenital Anomaly
}

\author{
Hitendra P Singh ${ }^{1}$, Sunil Kumar ${ }^{2}$, Neha Rautela ${ }^{3}$, Meraj Ahmad ${ }^{4}$
}

\begin{abstract} extents. Authors intend to present a case of incomplete synechiae of the oral cavity. cause aerodigestive problems in the neonatal period. normal except cleft palate. abnormalities, and improper eruption of teeth.

Clinical significance: As there are various types of presentations, the treatment needs to be individualized.

Keywords: Maxillo-mandibular fusion, Oral synechiae, Orofacial anomalies, Syngnathia.

International Journal of Head and Neck Surgery (2018): 10.5005/jp-journals-10001-1359
\end{abstract}

Aim: Fusion defects of maxilla and mandible are a rare congenital anomaly that affect the growth and development of patients in varying

Background: Congenital maxillo-mandibular fusions present with varying degree of involvement of mucosa, soft tissues and bone and can

Case description: A 5-day-old male child was referred from pediatrics for evaluation for complaints of inability to feed. On examination, a mucosal band was noted connecting the floor of the mouth with the hard palate, with free margins on both sides. After proper consent, the mucosal band was completely excised under local anesthesia and hemostasis was achieved. The rest of the oral cavity and oropharynx was

Conclusion: These types of anomalies have to be diagnosed as early as possible in the early neonatal life. Early diagnosis and appropriate management should be instituted to prevent risks of asphyxia, aspiration pneumonitis, growth retardation, malnutrition, facial growth

\section{BACKGROUND}

Fusion of maxilla and mandible can involve only the soft tissues or both hard and soft tissues of the oral cavity. It may present with respiratory or feeding difficulty and facial growth abnormalities due to temporomandibular joint fixation at a later age. ${ }^{1}$ Fusion of the maxilla and mandible mostly occurs in association with other oral and orofacial anomalies such as cleft lip and cleft palate. ${ }^{1-3}$ Decision to discuss this case was taken, first, to highlight this rare birth defect to the readers; secondly, our case did not find any place in the most accepted classifications of this condition.

\section{Case Description}

A 5-day-old neonate weighing $2 \mathrm{~kg}$ was referred to us from the Department of Pediatrics for evaluation and management of restricted mouth opening and inability to feed. The baby was a full-term born with normal vaginal delivery in a hospital without any adverse consequences. According to the mother since the time of birth, the neonate has not been able to open his mouth and feed. The child has been kept under observation with nasogastric tube feeding. There was no similar history in other siblings of the child. The patient was simply diagnosed as a case of tongue tie from the Department of Pediatrics and they have sent the child for its release. However, on examination of the oral cavity, it was observed that there was an incomplete fibrous band between the floor of the mouth and hard palate anteriorly (Fig. 1). He rest of the structures of the oral cavity could not be visualized.

After obtaining proper informed consent from the parents, the child was transferred to the ENT ward. Since it was not possible to intubate the patient, excision of fibrous attachment was planned under intravenous sedation. Once under sedation, the band was

\footnotetext{
${ }^{1-3}$ Department of ENT and Head-Neck Surgery, King George's Medical University, Lucknow, Uttar Pradesh, India

${ }^{4}$ Department of ENT, RDSO Hospital, Lucknow, Uttar Pradesh, India

Corresponding Author: Hitendra P Singh, Department of ENT and Head-Neck Surgery, King George's Medical University, Lucknow, Uttar Pradesh, India, Phone: +91 9456048923, e-mail: drhpsingh77@ gmail.com

How to cite this article: Singh HP, Kumar S, et al. Synechiae of the Oral Cavity with Cleft Palate: A Rare Congenital Anomaly. Int J Head Neck Surg 2018;9(4):128-130.

Source of support: Nil

Conflict of interest: None
}

excised and hemostasis achieved. After complete excision of the band, complete visualization of oral cavity was done. Remarkably, the child's tongue was normal (Fig. 2). On further inspection, presence of cleft palate involving both hard and soft palate areas could be noted (Fig. 3).

The child fared well in the recovery period. He was sent to the pediatrics and plastic surgery department for further management regarding cleft palate and low birth weight.

\section{Discussion}

Incidence of congenital birth defects in neonates is about $2.5 \%$. Congenital fusion defects of the maxilla and mandible with other anatomical oral and orofacial abnormalities are usually rare. ${ }^{3}$ Though congenital fibrous bands commonly involve either between alveolar ridges of the maxilla and mandible or between the tongue and palate, it can involve any part of the oral cavity. ${ }^{1,2}$ The term

(c) The Author(s). 20180pen Access This article is distributed under the terms of the Creative Commons Attribution 4.0 International License (https://creativecommons. org/licenses/by-nc/4.0/), which permits unrestricted use, distribution, and non-commercial reproduction in any medium, provided you give appropriate credit to the original author(s) and the source, provide a link to the Creative Commons license, and indicate if changes were made. The Creative Commons Public Domain Dedication waiver (http://creativecommons.org/publicdomain/zero/1.0/) applies to the data made available in this article, unless otherwise stated. 


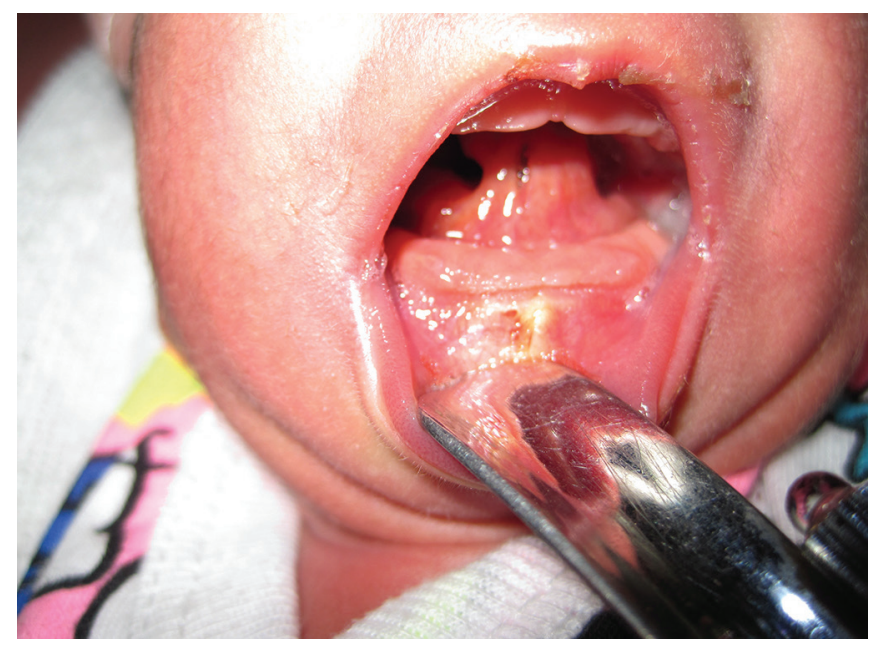

Fig. 1: Front view of the oral cavity showing incomplete congenital mucosal band (synechiae) between floor of mouth and palate

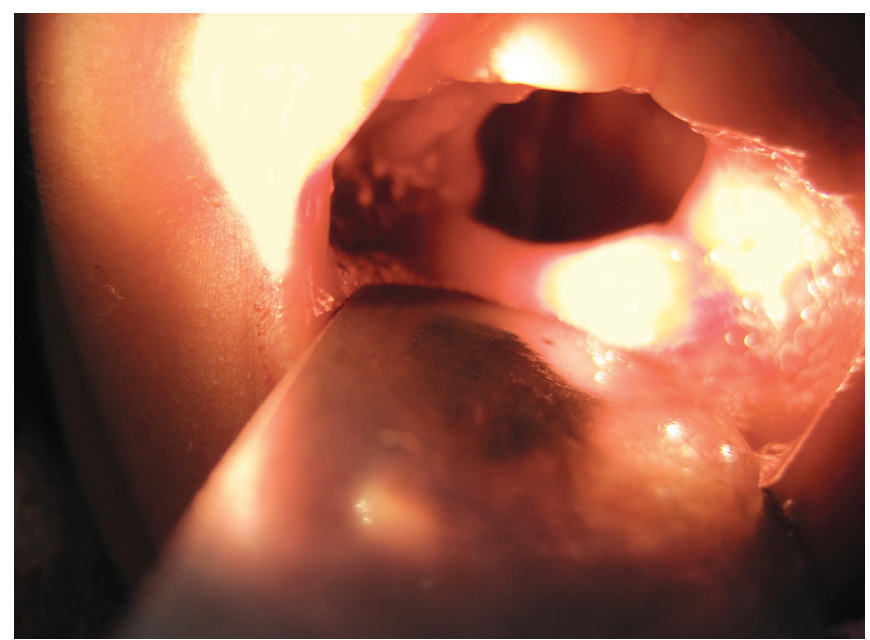

Fig. 3: Front view of the oral cavity after removal of mucosal band showing cleft palate

syngnathia denotes congenital fusion bands between maxilla and mandible and epithelium, connective tissue, muscle and bone all may be involved in the process. ${ }^{3}$ It is known as synostosis when it comprises of bones and soft tissues or synechiae when there is only involvement of soft tissues. Bony maxilla-mandibular fusion is an extremely rare anomaly.

Two classification systems of such fusion have been proposed by Dawson and colleagues ${ }^{4}$ and Laster and coworkers. ${ }^{5}$

Dawson divided the cases of syngnathia into:

- Type I: Simple - with no other birth defects in head and neck;

- Type II: Complex-with two subtypes:

- Type Ila: Syngnathia with aglossia;

- Type Ilb: Syngnathia with agenesis or hypoplasia of the proximal mandible.

Laster modified Dawson's classification system as:

- Type la: Simple anterior syngnathia characterized by bony fusion of the alveolar ridges and without other congenital deformities in head and neck

- Type Ib: Complex anterior syngnathia characterized by bony fusion of the alveolar ridges only and associated with other congenital deformities in head and neck

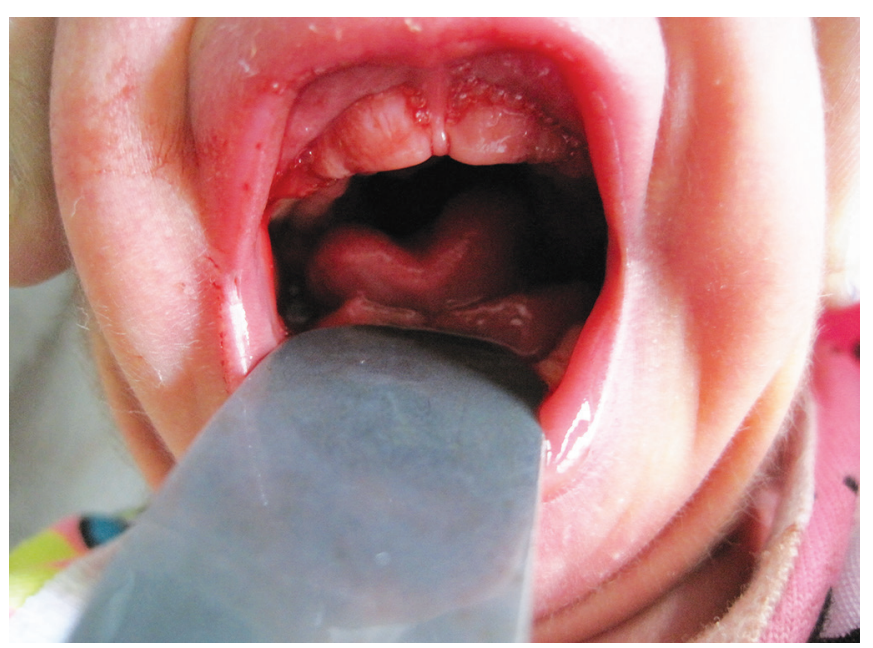

Fig. 2: Front view of the oral cavity after removal of mucosal band showing normal tongue

- Type lla:Simplezygomaticomandibular syngnathia characterized by bony fusion of the mandible to the zygomatic complex, causing only mandibular micrognathia

- Type Ilb: Complex zygomaticomandibular syngnathia characterized by bony fusion of the mandible to the zygomatic complex and associated with clefts or temporomandibular joint ankyloses.

However, both classification systems do not classify simple anterior incomplete synechiae with cleft palate into any type. A new system of classification which takes into consideration the fusion of soft tissues and bones separately along with the presence of other congenital orofacial anomalies should be devised.

Various causes have been considered as a reason for the syndrome; however, none has been proved. Some described the cause to include persistence of the buccopharyngeal membrane, ${ }^{6}$ amniotic constriction bands in the region of the developing branchial arches, environmental insults, drugs such as large doses of vitamin $A ., 8$

A proper radiological investigation including high resolution CT scan can support the clinical recognition of this condition and its nature. Such congenital bands interfere with feeding, breathing, general health of the patient, growth and development, intubation for anesthesia and difficulty in breathing, aspiration pneumonitis and other problems. ${ }^{8}$ Early intervention is needed to secure airway followed by management of feeding problems as delayed intervention in the case of maxillo-mandibular fusion can predispose the neonate to asphyxia, aspiration pneumonitis, malnutrition, growth retardation, poor growth of the facial skeleton, and poorly aligned dental eruption. However, treatment varies as per the extent and nature of anomalies.

\section{Conclusion}

These type of anomalies have to be diagnosed as early as possible in the early neonatal life. Early diagnosis helps in institution of appropriate management plan for the child. Early intervention is needed to secure airway followed by management of feeding problems as delayed intervention in the case of maxillo-mandibular fusion can predispose the neonate to asphyxia, aspiration pneumonitis, malnutrition, growth retardation, poor growth of the 
facial skeleton, and poorly aligned dental eruption. Management plan varies as per the need of the individual case.

\section{Clinical Significance}

Congenital fusion of maxilla and mandible is a rare anomaly. It may present with aerodigestive problems and facial deformities. As there are various types of presentations, treatment needs to be individualized.

\section{References}

1. Mortazavi $\mathrm{SH}$, Motamedi MH. Congenital fusion of the jaws. Indian J Pediatr 2007;74:4168. DOI: 10.1007/s12098-007-0071-5.

2. Mir MA, lqbal S, et al. Syngnathia without any other associated anomaly very rare case report. Internet J Plast Surg 2007;4:1.

3. Tanrikulu R, Erol B, et al. Congenital alveolar synechiae: a case report. Br Dent J 2005;198:81-82. DOI: 10.1038/sj.bdj.4811971.
4. Dawson KH, Gruss JS, et al. Congenital bony syngnathia: a proposed classification. Cleft Palate Craniofac J 1997;34:141-146. DOI: 10.1597/1545-1569_1997_034_0141_cbsapc_2.3.co_2.

5. Laster Z, Temkin D, et al. Complete bony fusion of the mandible to the zygomatic complex and maxillary tuberosity: case report and review. Int J Oral Maxillofac Surg 2001;30:75-79. DOI: 10.1054/ijom. 2000.0009.

6. Verloesa $\mathrm{A}$, Raoula $\mathrm{M}$, et al. Bony syngnathia, vertebral segmentation defect, coloboma, microcephaly and mental retardation: confirmation of Dobrow syndrome and review of syndromal syngnathias. Clin Dysmorphol 2004;13:205-211. DOI: 10.1097/00019605-20041000000002.

7. Parkins GE, Boamah MO. Congenital maxillomandibular syngnathia: Case report. J Craniomaxillofac Surg 2009;37:2768. DOI: 10.1016/ j.jcms.2009.01.001.

8. Shams MG, Motamedi MH, et al. Congenital fusion of the maxilla and mandible: Brief case report. Oral Surg Oral Med Oral Pathol Oral Radiol Endod 2006;102:e13. DOI: 10.1016/j.tripleo.2005.10.051. 